\title{
Article \\ Bacterial Pathogens and Evaluation of a Cut-Off for Defining Early and Late Neonatal Infection
}

\author{
Pavla Kucova ${ }^{1}$, Lumir Kantor ${ }^{2, *}$, Katerina Fiserova ${ }^{1}$, Jakub Lasak ${ }^{2}{ }^{\circledR}$, Magdalena Röderova ${ }^{1}$ and Milan $\operatorname{Kolar}^{1}{ }^{1}$ \\ 1 Department of Microbiology, Faculty of Medicine and Dentistry, Palacky University Olomouc and University \\ Hospital Olomouc, 77900 Olomouc, Czech Republic; pavla.kucova@fnol.cz (P.K.); \\ katerina.fiserova@fnol.cz (K.F.); magdalena.roderova@upol.cz (M.R.); milan.kolar@fnol.cz (M.K.) \\ 2 Neonatal Department, University Hospital Olomouc, 77900 Olomouc, Czech Republic; jakub.lasak@fnol.cz \\ * Correspondence: kantorl@senat.cz
}

check for updates

Citation: Kucova, P.; Kantor, L.; Fiserova, K.; Lasak, J.; Röderova, M.; Kolar, M. Bacterial Pathogens and Evaluation of a Cut-Off for Defining Early and Late Neonatal Infection. Antibiotics 2021, 10, 278. https:// doi.org/10.3390/antibiotics10030278

Academic Editor: Anna Psaroulaki

Received: 16 February 2021

Accepted: 7 March 2021

Published: 9 March 2021

Publisher's Note: MDPI stays neutral with regard to jurisdictional claims in published maps and institutional affiliations.

Copyright: (C) 2021 by the authors. Licensee MDPI, Basel, Switzerland. This article is an open access article distributed under the terms and conditions of the Creative Commons Attribution (CC BY) license (https:// creativecommons.org/licenses/by/ $4.0 /)$.

\begin{abstract}
Bacterial infections are an important cause of mortality and morbidity in newborns. The main risk factors include low birth weight and prematurity. The study identified the most common bacterial pathogens causing neonatal infections including their resistance to antibiotics in the Neonatal Department of the University Hospital Olomouc. Additionally, the cut-off for distinguishing earlyfrom late-onset neonatal infections was assessed. The results of this study show that a cut-off value of $72 \mathrm{~h}$ after birth is more suitable. Only in case of early-onset infections arising within $72 \mathrm{~h}$ of birth, initial antibiotic therapy based on gentamicin with ampicillin or amoxicillin/clavulanic acid may be recommended. It has been established that with the 72-h cut-off, late-onset infections caused by bacteria more resistant to antibiotics may be detected more frequently, a finding that is absolutely crucial for antibiotic treatment strategy.
\end{abstract}

Keywords: newborn; infection; bacteria; antibiotic therapy

\section{Introduction}

Neonatal infections may be defined as infectious diseases occurring in newborns within 4 weeks after birth. They may be classified as early-onset or late-onset, with the cut-off for distinguishing early- from late-onset infections ranging between $72 \mathrm{~h}$ and 7 days.

Early-onset neonatal infections are caused by microorganisms transmitted in utero or as the baby moves down the birth passage (antepartum or intrapartum), with $85 \%$ of them occurring within $24 \mathrm{~h}$ from birth [1,2]. The most common etiologic agents are Escherichia coli, Streptococcus agalactiae (GBS), and Listeria monocytogenes. Less frequently, chlamydias and mycoplasmas are shown to play an etiologic role [3-5]. For initial antibiotic therapy, ampicillin or amoxicillin with clavulanic acid, combined with gentamicin are recommended $[2,6,7]$. In the literature, however, information is available about increasing resistance of Escherichia coli to antibiotics including aminopenicillins combined with inhibitors of bacterial beta-lactamases (ampicillin/sulbactam and amoxicillin/clavulanic acid) and potential failure of antibiotic therapy [8-11]. The risk factors for the development of early-onset infections include vaginal colonization with GBS, prelabor rupture of membranes, prematurity, multiple abortions, maternal malnutrition, and congenital abnormalities [12-14].

Late-onset neonatal infections are caused by bacteria associated with hospital care. Multidrug-resistant bacteria are frequently responsible for these infections. Important sources are artificial materials, in particular, cannulas or catheters [13,15]. The most common bacterial pathogens are Staphylococcus aureus, coagulase-negative staphylococci, Klebsiella pneumoniae, Escherichia coli, Enterobacter spp., Serratia marcescens, Pseudomonas aeruginosa, Acinetobacter baumannii, anaerobic bacteria, and yeasts [16-18]. The risk factors for acquiring infections include prematurity, congenital abnormalities, and invasive care such as central venous catheter placement or respiratory support [13,19]. In many cases, 
antibiotic therapy requires application of antibacterial drugs effective against multidrugresistant bacteria such as carbapenems, glycopeptides, and aminoglycosides in relevant combinations [20].

A very important part of the overall therapeutic approach to neonatal infections is microbiological examination of adequate clinical materials, in particular, blood and cerebrospinal fluid cultures. The obtained results allow targeted antibiotic therapy based on identification of bacterial pathogens and determination of their susceptibility/resistance to antibiotics. Under defined conditions, nasopharyngeal and rectal swabs, pharyngeal aspirate, urine, and other specimens may also be of clinical importance if very carefully interpreted [21].

Our study aimed to assess the cut-offs for distinguishing early- from late-onset neonatal infections and determine the most frequent bacterial pathogens causing or suspected of causing neonatal infections, including their resistance to antibacterial drugs.

\section{Results}

Over a 3-year period, a total of 7221 newborns were either born or transported to the Neonatal Department of the University Hospital Olomouc. Neonatal infections were treated in 364 cases (5\%), in whom 263 bacterial and 59 mycotic pathogens were isolated.

Clinical sepsis $(72 \%)$ was most common in newborns, followed by bloodstream infections (13\%) and pneumonia (9\%); less frequent were meningitis (1\%) and necrotizing enterocolitis (1\%). In $4 \%$ of newborns treated for infections of unclear origin, no bacterial pathogens were isolated.

The sample consisted of the following gestational age subgroups: term $38 \%$, moderate to late preterm $28 \%$, very preterm $20 \%$ and extremely preterm newborns $14 \%$. The birth weight subgroups were as follows: normal birth weight $41 \%$, low birth weight $26 \%$, very low birth weight $14 \%$ and extremely low birth weight $19 \%$.

The most frequently isolated bacteria were Escherichia coli (22\%), Klebsiella pneumoniae $(12 \%)$, coagulase-negative staphylococci (12\%), and Staphylococcus aureus $(10 \%)$ (Table 1$)$. The results show that Enterobacterales accounted for more than half (56\%) of all bacterial pathogens. Streptococcus agalactiae caused infection in only nine newborns and Listeria monocytogenes was detected in a single infant. Besides bacterial pathogens, Candida spp. were responsible for 59 cases of infections (majority of which was treated topically), with Candida albicans causing infections in $47(<1 \%)$ newborns. Candida parapsilosis and Candida tropicalis were confirmed as etiologic agents in only 7 and 5 neonatal infections, respectively.

Overall, 6\% of newborns in 2015 and 5\% in both 2016 and 2017 were treated with antibiotics for confirmed or suspected early- or late-onset infection. Table 2 shows bacterial pathogens causing early- and late-onset infections as defined by the two cut-offs (72 $\mathrm{h}$ and 7 days).

Table 1. Bacteria isolated from newborns prior to initiation of antibiotic therapy.

\begin{tabular}{ccc}
\hline Bacterial Species & No. of Isolates & Percentage \\
\hline Escherichia coli & 57 & 22 \\
Klebsiella pneumoniae & 31 & 12 \\
Coagulase-negative staphylococci & 31 & 12 \\
Staphylococcus aureus & 25 & 10 \\
Enterobacter cloacae & 16 & 6 \\
Klebsiella oxytoca & 16 & 6 \\
Stenotrophomonas maltophilia & 15 & 6 \\
Pseudomonas aeruginosa & 14 & 5 \\
Enterococcus faecalis & 11 & 4 \\
Streptococcus agalactiae & 9 & 3 \\
Burkholderia cepacia complex & 8 & 3 \\
Citrobacter freundii & 4 & 2 \\
Ralstonia picketii/insidiosa & 4 & 2 \\
Pseudomonas putida & 2 & 1 \\
\hline
\end{tabular}


Table 1. Cont.

\begin{tabular}{ccc}
\hline Bacterial Species & No. of Isolates & Percentage \\
\hline Acinetobacter baumannii & 2 & 1 \\
Klebsiella aerogenes & 2 & 1 \\
Enterobacter kobei & 2 & 1 \\
Serratia marcescens & 2 & 1 \\
Haemophilus influenzae type b & 2 & 1 \\
Enterobacter asburiae & 2 & 1 \\
Others & 8 & 3 \\
\hline Legend: others-bacteria isolated only once (Salmonella Enteritidis, Providencia rettgeri, Proteus mirabilis, Morganella \\
morganii, Listeria monocytogenes, Streptococcus anginosus, Streptococcus intermedius, and Enterococcus faecium).
\end{tabular}

Table 2. Numbers of bacterial/mycotic pathogens from newborns treated with antibiotics with regard to different cut-offs for distinguishing between early- and late-onset infections.

\begin{tabular}{|c|c|c|c|c|c|}
\hline \multirow[t]{2}{*}{ Bacterial Pathogen } & \multicolumn{2}{|c|}{ Early-Onset (Absolute No.) } & \multicolumn{2}{|c|}{ Late-Onset (Absolute No.) } & \multirow[b]{2}{*}{$p$-Value } \\
\hline & $\leq 72 \mathrm{~h}$ & $\leq 7$ days & $>72 \mathrm{~h}$ & $>7$ days & \\
\hline Escherichia coli & 15 & 26 & 42 & 31 & $<0.001$ \\
\hline Klebsiella pneumoniae & 10 & 19 & 21 & 12 & 0.002 \\
\hline Coagulase-negative staphylococci & 4 & 15 & 27 & 16 & $<0.001$ \\
\hline Staphylococcus aureus & 3 & 12 & 22 & 13 & 0.002 \\
\hline Enterobacter cloacae & 5 & 9 & 11 & 7 & 0.063 \\
\hline Klebsiella oxytoca & 2 & 7 & 14 & 9 & 0.031 \\
\hline Stenotrophomonas maltophilia & 1 & 7 & 14 & 8 & 0.016 \\
\hline Pseudomonas aeruginosa & 1 & 8 & 13 & 6 & 0.008 \\
\hline Enterococcus faecalis & 3 & 7 & 8 & 4 & 0.063 \\
\hline Streptococcus agalactiae & 8 & 9 & 1 & 0 & 0.500 \\
\hline Burkholderia cepacia complex & 0 & 3 & 8 & 5 & 0.125 \\
\hline Citrobacter freundii & 1 & 3 & 3 & 1 & \\
\hline Ralstonia picketii/insidiosa & 0 & 3 & 4 & 1 & \\
\hline Pseudomonas putida & 0 & 0 & 2 & 2 & \\
\hline Acinetobacter baumannii & 0 & 1 & 2 & 1 & \\
\hline Klebsiella aerogenes & 0 & 1 & 2 & 1 & \\
\hline Enterobacter kobei & 0 & 0 & 2 & 2 & \\
\hline Serratia marcescens & 0 & 0 & 2 & 2 & \\
\hline Haemophilus influenzae type b & 1 & 2 & 1 & 0 & \\
\hline Enterobacter asburiae & 0 & 1 & 2 & 1 & \\
\hline Other bacteria & 3 & 6 & 5 & 2 & \\
\hline Mycotic pathogen & $\leq 72 \mathrm{~h}$ & $\leq 7$ days & $>72 \mathrm{~h}$ & $>7$ days & \\
\hline Candida albicans & 3 & 24 & 44 & 23 & $<0.001$ \\
\hline Candida parapsilosis & 0 & 3 & 7 & 4 & 0.125 \\
\hline Candida tropicalis & 0 & 2 & 5 & 3 & \\
\hline
\end{tabular}

Legend: $p$-values are given for bacterial and Candida species with a number of isolates $>5$.

When the 72-h cut-off for developing symptoms of early-onset infection was applied, a total of 57 pathogens were isolated, mostly enterobacteria (58\%). The most frequently isolated species were Escherichia coli (26\%) and Klebsiella pneumoniae (18\%). The use of the other cut-off, i.e., early-onset infections in the first 7 days of life, resulted in isolation of 139 pathogenic bacteria. The most common organisms were enterobacteria $(47 \%)$, mainly Escherichia coli (19\%) and Klebsiella pneumoniae (14\%), followed by Gram-positive bacteria $(31 \%)$, mainly coagulase-negative staphylococci (11\%) and Staphylococcus aureus $(9 \%)$.

In case of late-onset infections defined by the 72-h cut-off, a total of 206 bacterial pathogens were isolated. The most common were enterobacteria $(48 \%)$, in particular, Escherichia coli (20\%), followed by Klebsiella pneumoniae (10\%) and Enterobacter cloacae (5\%). Further, there were $28 \%$ of Gram-positive bacteria (coagulase-negative staphylococci in $13 \%$ and Staphylococcus aureus in 11\%). When late-onset neonatal infections were defined 
by symptoms occurring from the eighth day, 124 bacterial pathogens were identified; the most frequent species were Escherichia coli (25\%) and Klebsiella pneumoniae (10\%).

Assessment of the two cut-offs (i.e., $\leq 72 \mathrm{~h}$ and $\leq 7$ days of life) showed that the presence changed for most bacterial species. This was obvious in case of coagulasenegative staphylococci; when the 72-h cut-off was applied, only 4 out of 31 cases could be characterized as early-onset, as compared with 15 cases when using the 7-day cut-off. Similar differences were observed for Staphylococcus aureus, Escherichia coli, and Klebsiella pneumoniae (Figure 1). Yet another example may be non-fermenting Gram-negative bacteria. Out of 14 cases with Pseudomonas aeruginosa infection, 1 and 8 were interpreted as earlyonset according to the 72-h and 7-day cut-offs, respectively. Similarly, among 15 cases in which Stenotrophomonas maltophilia was isolated, only 1 was early-onset when the 72-h cut-off was used, as compared with 7 cases when applying the other cut-off. In case of Candida albicans infections, it is clear that according to the 72-h cut-off, only 3 out of 47 cases could be defined as early-onset, while with the 7-day cut-off, it was 24 cases (Figure 1).
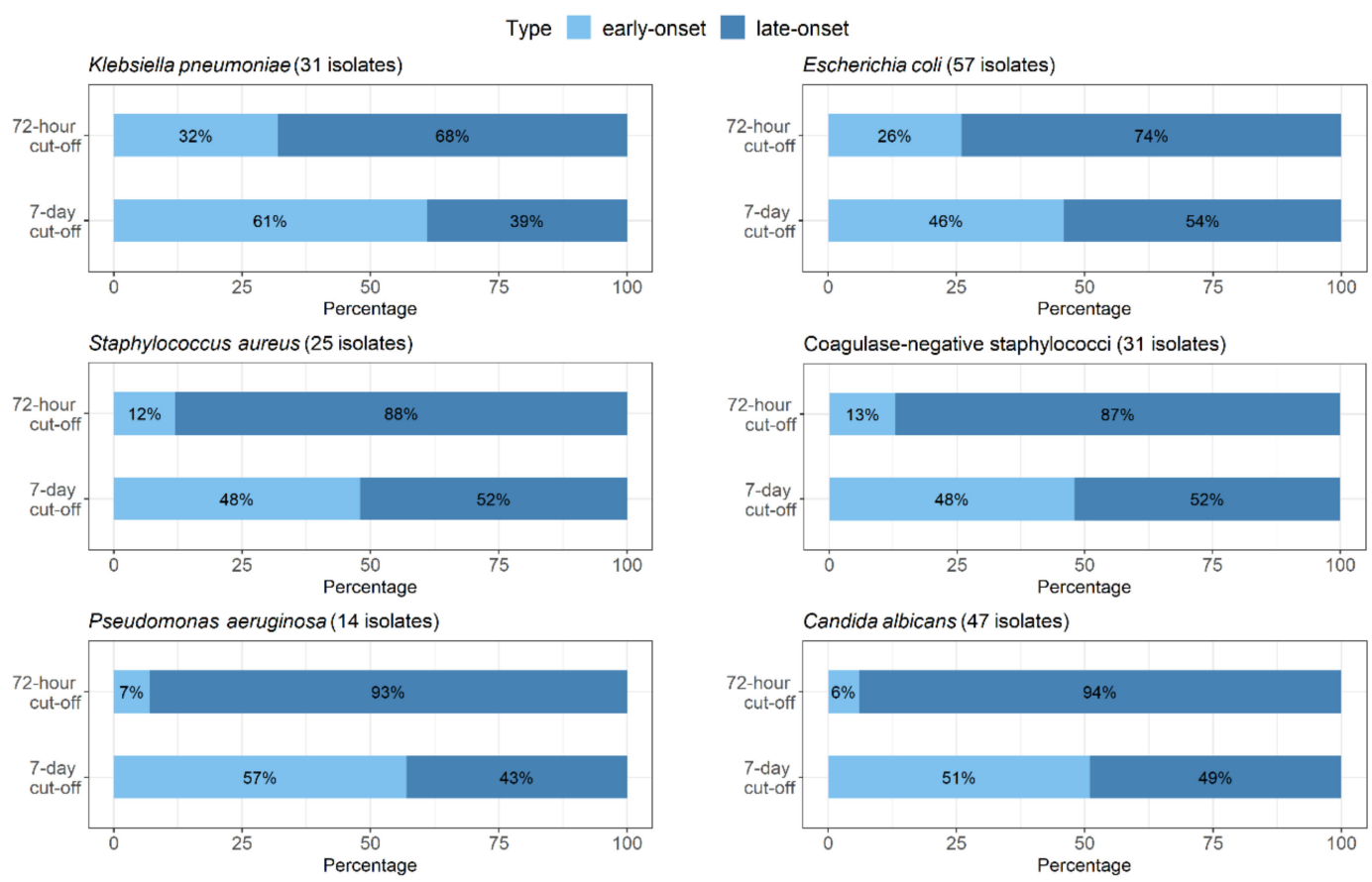

Figure 1. Proportional representation of early- and late-onset infections with regard to both cut-offs (72-h and 7-day) shown for Klebsiella pneumoniae, Escherichia coli, Staphylococcus aureus, coagulase-negative staphylococci, Pseudomonas aeruginosa, and Candida albicans.

Table 3 shows the numbers of suspected or confirmed causative bacteria isolated from newborns treated with antibiotics as well as the numbers of newborns in whom no bacterial pathogen was detected. According to the results, only one bacterial species was isolated in $76 \%$ of newborns, more than one microorganisms were isolated in $9 \%$ and no etiologic agent was identified in $15 \%$ of infants with clinical sepsis.

Table 3. Identification of etiologic agents causing/suspected of causing neonatal infections.

\begin{tabular}{cccc}
\hline $\begin{array}{c}\text { Etiology of Confirmed or } \\
\text { Suspected Infections }\end{array}$ & $\begin{array}{c}\mathbf{2 0 1 5} \\
\text { (Absolute No.) }\end{array}$ & $\begin{array}{c}\mathbf{2 0 1 6} \\
\text { (Absolute No.) }\end{array}$ & $\begin{array}{c}\mathbf{2 0 1 7} \\
\text { (Absolute No.) }\end{array}$ \\
\hline No identified pathogen & 19 & 23 & 14 \\
Monomicrobial etiology & 101 & 81 & 94 \\
Polymicrobial etiology & 12 & 9 & 11 \\
Total & 132 & 113 & 119 \\
\hline
\end{tabular}


The results suggest relatively good susceptibility of the most frequently isolated enterobacteria (Escherichia coli, Klebsiella pneumoniae, Enterobacter cloacae, and Klebsiella oxytoca) to antibacterial drugs with the exception of ampicillin and cefazolin. Production of broad-spectrum beta-lactamases (only ESBL and AmpC types) was confirmed in eight strains, i.e., 6\% of isolated enterobacteria (Table 4). All those strains were isolated from neonates who developed infection from day 4 of life onwards. Resistance to meropenem was not noted.

Table 4. Broad-spectrum beta-lactamase (ESBL- and AmpC only)-positive enterobacteria.

\begin{tabular}{ccc}
\hline Species & No. of Strains & Type of Broad-Spectrum Beta-Lactamase \\
\hline Klebsiella pneumoniae & 3 & ESBL-CTX-M-15 \\
Klebsiella pneumoniae & 1 & ESBL-CTX-M-9 \\
Escherichia coli & 2 & ESBL-CTX-M-15 \\
Enterobacter cloacae & 1 & AmpC-EBC \\
Citrobacter freundii & 1 & AmpC-CIT \\
\hline
\end{tabular}

Pulsed-field gel electrophoresis (PFGE) of 3 CTX-M-15-positive Klebsiella pneumonia and 2 CTX-M-15-positive Escherichia coli strains showed that those were strains with unique restriction genetic profiles. Therefore, clonal horizontal transmission was ruled out (Figures 2 and 3).

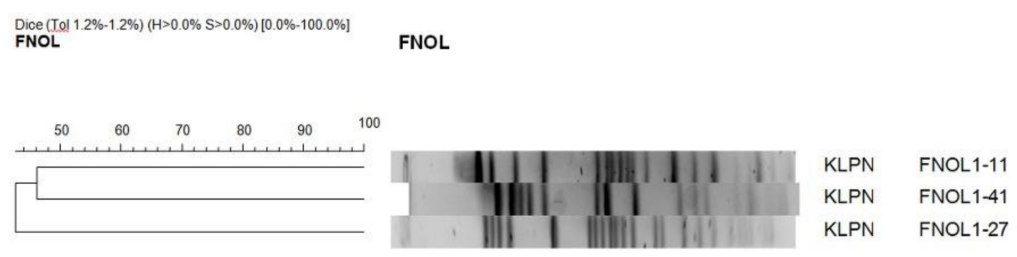

Figure 2. Pulsed-field gel electrophoresis (PFGE) of 3 CTX-M-15-positive Klebsiella pneumonia strains.
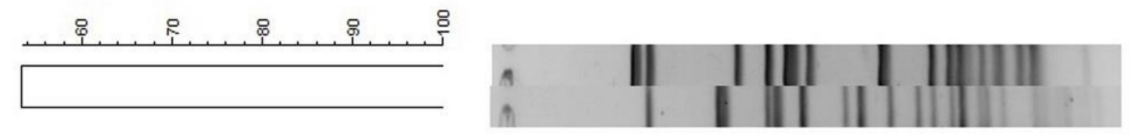

Figure 3. PFGE of 2 CTX-M-15-positive Escherichia coli strains.

The most frequently isolated Gram-positive bacteria, Staphylococcus aureus, was 100\% susceptible to oxacillin. It means that methicillin-resistant Staphylococcus aureus (MRSA) was not detected. Very high susceptibility was found to ciprofloxacin, erythromycin, clindamycin, gentamicin, and glycopeptides (vancomycin and teicoplanin). Higher resistance levels were documented in coagulase-negative staphylococci, but vancomycin and teicoplanin were found to be very effective. Isolated strains of Enterococcus faecalis and Streptococcus agalactiae were $100 \%$ susceptible to ampicillin and glycopeptides (vancomycin and teicoplanin).

Susceptibility of the most frequently isolated bacterial pathogens to antibiotics is illustrated in Tables 5 and 6. 
Table 5. Susceptibility of enterobacteria to selected antibiotics (percentages).

\begin{tabular}{ccccc}
\hline Antibiotic/Pathogen & Escherichiacoli & Klebsiella pneumoniae & Klebsiella oxytoca & Enterobacter cloacae \\
\hline AMI & 95 & 100 & 100 & 100 \\
AMP & 28 & 0 & 0 & 0 \\
AMS & 84 & 90 & 100 & 0 \\
CIP & 98 & 90 & 100 & 100 \\
COL & 100 & 87 & 94 & 81 \\
CPM & 98 & 90 & 100 & 94 \\
CRX & 95 & 90 & 100 & 0 \\
CTX & 95 & 90 & 100 & 81 \\
CTZ & 98 & 90 & 44 & 0 \\
CZL & 77 & 77 & 100 & 100 \\
GEN & 88 & 90 & 100 & 100 \\
MER & 100 & 100 & 100 & 81 \\
PPT & 96 & 90 & 90 & 100 \\
\hline
\end{tabular}

Legend: AMI—amikacin, AMP—ampicillin, AMS—ampicillin/sulbactam, CIP—ciprofloxacin, COL—colistin, CPM—cefepime, CRXcefuroxime, CTX—cefotaxime, CTZ—ceftazidime, CZL—cefazolin, GEN—gentamicin, MER—meropenem, PPT—piperacillin/tazobactam, TOB-tobramycin.

Table 6. Susceptibility of Staphylococcus aureus and coagulase-negative staphylococci to selected antibiotics (percentages).

\begin{tabular}{ccc}
\hline Antibiotic/Pathogen & Staphylococcus aureus & Coagulase-Negative Staphylococci \\
\hline OXA & 100 & 28 \\
CIP & 100 & 57 \\
CLI & 80 & 51 \\
TEI & 100 & 93 \\
VAN & 100 & 93 \\
ERY & 80 & 30 \\
GEN & 80 & 45 \\
\hline
\end{tabular}

Legend: OXA—oxacillin, CLI—clindamycin, TEI-teicoplanin, VAN—vancomycin, ERY—erythromycin.

\section{Discussion}

An indispensable part of the therapeutic approach to neonatal infections is application of antibacterial drugs immediately after establishing the diagnosis or as soon as strong suspicion arises. Antibiotic regimens should consider microbiological examinations of the newborn and its mother as well as local results of surveillance of the most common bacterial pathogens and their resistance to antibiotics. Based on microbiology test results, an integral part of the overall therapeutic approach, targeted antibiotic therapy should be administered.

Over the study period, a total of 7221 newborns were hospitalized in the Neonatal Department of the University Hospital Olomouc, with bacterial infections being treated in $5 \%$ of them. This percentage is very high for several reasons. Some of the neonates were transported to our tertiary neonatal unit due to serious health complications. As some preterm neonates were treated more than once, the percentage reflects the number of treated cases rather than the number of treated children. Therefore, the rate is not the incidence of neonatal infections, but the incidence of antibiotic treatment, preemptive in some cases. The study results suggest that the most common bacterial agents causing or suspected of causing neonatal infections were enterobacteria ( $52 \%$ of all isolated pathogens) and staphylococci $(21 \%)$. The most frequent causative species were Escherichia coli $(22 \%)$, Klebsiella pneumoniae (12\%), coagulase-negative staphylococci $(12 \%)$, and Staphylococcus aureus (10\%). Candida spp. infections were caused by Candida albicans in the vast majority of cases $(80 \%)$. These results are consistent with those published by Russell who found that in neonatal infections, the most common isolates were Escherichia coli, coagulase-negative staphylococci, Staphylococcus aureus, and Enterococcus spp. [22]. Shane et al. reported that 
in neonatal infections, Streptococcus agalactiae (43\%) and Escherichia coli (29\%) were most frequently isolated. These species belong to the most important pathogens contributing to the development of early-onset neonatal infections. According to the authors, lateonset infections were caused by Staphylococcus aureus, coagulase-negative staphylococci, enterococci, enterobacteria, and Streptococcus pyogenes [23]. In a study by Bulkowstein et al., the most common pathogens causing early-onset infections were Escherichia coli (34\%), Streptococcus agalactiae (22\%), Klebsiella pneumoniae (13\%), Enterococcus faecalis (9\%), and Staphylococcus aureus (5\%). The spectrum of pathogens was similar for late-onset infections; most frequently, the authors isolated Escherichia coli (29\%), Streptococcus pneumoniae (13\%), Staphylococcus aureus (9\%), and Klebsiella pneumoniae (7\%) [24].

Given the present results, the 72-h cut-off appears to be more suitable for distinguishing early- from late-onset neonatal infections. Therefore, the use of a different antibiotics could be advised. Within $72 \mathrm{~h}$ of birth, microorganisms transmitted from the mother in utero or during birth were isolated more frequently. However, when infections developing in the first 7 days of life were considered as early-onset, more bacteria associated with nosocomial infections were isolated. Our results indicate that with the 72-h cut-off, bacteria originating from the mother (mainly Streptococcus agalactiae) were detected. At the same time, the frequency of non-fermenting bacteria (e.g., Stenotrophomonas maltophilia and Pseudomonas aeruginosa) was very low. With the 7-day cut-off for early neonatal infections, almost a double number of bacterial pathogens was identified. These bacteria show higher levels of resistance to antibiotics, and they are very often associated with hospital care and nosocomial infections. It should be emphasized that infections caused by enterobacteria producing broad-spectrum beta-lactamases would also fall into the category of early-onset infections if the 7-day cut-off was used. However, if the 72-h cut-off was applied, all these infections would be characterized as late-onset. Alternatively, bacterial strains were detected that tend to be related to the use of long-term central venous catheters, in particular coagulase-negative staphylococci. It has been established that with the 72-h cut-off, late-onset infections caused by bacteria more resistant to antibiotics may be detected more frequently, a finding that is absolutely crucial for antibiotic treatment strategy.

Infections caused by Candida spp. are associated with significant morbidity and mortality in infants. As with bacterial infections, premature babies with extremely low birth weight (less than $1000 \mathrm{~g}$ ) are most at risk of mycotic infections [25]. A rather serious disease of premature neonates is candidiasis, which can manifest as candidemia, urinary tract infection, or as impairment of any tissue or structure. The risk factors for developing candidiasis include prematurity, central vascular catheterization, abdominal surgery, necrotizing enterocolitis, exposure to broad-spectrum antibacterial agents (e.g., third-generation cephalosporins and carbapenems), parenteral nutrition, antacid use, and endotracheal intubation [26]. The use of catheters or endotracheal tubes destroys the body's natural barriers, allowing yeasts to penetrate, multiply, and invade sterile body areas. It is, therefore, clear that mycotic infection would not be possible without prior colonization. According to Roilides, the species most commonly occurring in pediatric patients are Candida albicans (50\%), Candida parapsilosis (21\%), and Candida tropicalis (10\%) [27]. The same species were also most frequent in the present study. The highest rates of yeasts were noted after the first $72 \mathrm{~h}$ of life. In these cases, it is more preferable to use the 72-h cut-off for early neonatal infections, since almost 10 times less yeasts were detected compared to the 7-day cut-off.

In the present study, GBS accounted for a very small proportion (3\%) of bacterial pathogens identified over the 3-year period. This species mainly plays a role in early-onset infections. This fact was confirmed by the present study, with 8 out of 9 GBS strains being isolated in the first $72 \mathrm{~h}$ of life. It may be calculated that GBS neonatal infection affected 1.2 newborns per 1000 live births. According to Strakova et al., the incidence of invasive streptococcal neonatal infections ranged from 0.7 to 1.0 cases per 1000 live births in 2001 and 2002 [28]. Simetka et al. reported early-onset GBS infections in 1.2 newborns per 1000 live births in 2003-2005 [29]. These findings may be explained by very effective prophylaxis as early as in the prenatal period, that is screening of all pregnant women between 35 and 
37 weeks of gestation, early laboratory diagnosis and relevant prepartum/intrapartum antibiotic prophylaxis [30-32].

In the present study, antimicrobial susceptibility testing showed relatively high efficacy of antibiotics. No MRSA strains or vancomycin-resistant enterococci were detected. Production of broad-spectrum beta-lactamases (CTX-M-15, CTX-M-9, EBC, and CIT) was confirmed in only $6 \%$ of enterobacteria with unique genetic profiles; no clonal spread was confirmed. On the other hand, a considerable therapeutic problem is posed by multidrugresistant strains of Stenotrophomonas maltophilia and Burkholderia cepacia complex susceptible to antibiotics contraindicated in neonatal care.

The main limitation of the study is its retrospective character. In addition, data from only one neonatal center were processed. It is most crucial to follow local antimicrobial resistance surveillance results when choosing initial antibiotic treatment.

\section{Material and Methods}

The primary outcome of the study is to evaluate the cut-offs for distinguishing earlyfrom late-onset neonatal infections. In neonatology, there are two most used cut-offs. They are $72 \mathrm{~h}$ of life and 7 days of life $[1,2,6,11,13]$. The aim of the study was to evaluate these existing and widely used cut-offs, based on bacteria isolated in specific postnatal age. We did not want to suggest a new cut-off. The secondary outcome can be characterized as the determination of the most frequent bacterial/mycotic pathogens causing or suspected of causing neonatal infections, including resistance to antibacterial drugs.

Biological samples (urine, stools, blood cultures, venous cannulas, cerebrospinal fluid, bronchoalveolar lavage fluid, axillary, throat, nasal, ear, conjunctival, and wound swabs) were obtained from newborns before antibiotic treatment. All biological samples were collected only as part of standard clinical care and active bacterial surveillance program.

Patients' parents gave informed consent to hospitalization, sample collection, and anonymous enrollment in the study. Ethics committee approval was not required as the study did not interfere with the diagnostic and therapeutic process.

The case inclusion criterion was antibiotic treatment, irrespective of infection type, provided to newborns staying in the Neonatal Department of the University Hospital Olomouc in 2015-2017. No patient treated with antibiotics was excluded from the study. To define infections, the modified NEO-KISS criteria were used for early- as well as lateonset sepsis.

Bacterial isolates were identified by MALDI-TOF MS (Biotyper Microflex, Bruker Daltonics, Bremen, Germany) [33]. Each identified strain was included only once in the database.

Bacteria isolated from blood or cerebrospinal fluid were considered to be etiologic agents. If a newborn was treated with antibiotics and bacteria were isolated from other samples, the bacteria were identified as a suspected etiologic agent.

Susceptibility to antibiotics was determined by using the microdilution method in accordance with the EUCAST recommendations [34]. Production of ESBLs and AmpC-type beta-lactamases was detected by relevant phenotypic tests and confirmed by PCR detecting genes specific for particular beta-lactamase types [35].

The similarity of 3 CTX-M-15-positive Klebsiella pneumoniae and 2 CTX-M-15-positive Escherichia coli isolates was assessed with PFGE. Bacterial DNA was isolated using a technique described by Husickova et al. and digested by the $\mathrm{XbaI}$ restriction endonuclease (New England Biolabs, Ipswich, MA, USA) for $24 \mathrm{~h}$ at $37^{\circ} \mathrm{C}$ [36]. The obtained DNA fragments were separated by PFGE on $1.2 \%$ agarose gel for $24 \mathrm{~h}$ at $6 \mathrm{~V} / \mathrm{cm}$ and pulse times of 2-35 s. Subsequently, the gel was stained with ethidium bromide. The resulting restriction profiles were analyzed with the GelCompar II software (Applied Maths, Kortrijk, Belgium) using the Dice coefficient (1.2\%) for comparing similarity and unweighted pair group method with arithmetic means for cluster analysis. The results were interpreted according to criteria described by Tenover et al. [37]. 
Statistical analyses were conducted using IBM SPSS Statistics version 22 (IBM, New York City, NY, USA) and the statistical environment R, version 4.0.2. The presence of bacteria assessed according to both cut-offs was compared with the McNemar's one-sided test. The tests were performed at a 0.05 level of significance.

\section{Conclusions}

The results clearly show that the therapeutic approach to neonatal infections must be based on their character including classification as early-/late-onset. As a cut-off value, $72 \mathrm{~h}$ after birth are more suitable. At the same time, it must be stressed that microbiological tests are necessary to allow targeted antibiotic therapy including application of adequate antibiotics if multidrug-resistant bacterial pathogens are detected. The results of this study confirm that only in case of early-onset infections arising within $72 \mathrm{~h}$ of birth, initial antibiotic therapy based on gentamicin with ampicillin or amoxicillin/clavulanic acid may be recommended. It is also clear that initial antibiotic treatment must be based on local surveillance of the most common bacterial pathogens and their resistance to antibiotics.

Author Contributions: Conceptualization, P.K. and M.K.; methodology, M.K. and L.K.; validation, M.K., L.K., and J.L.; formal analysis, P.K. and K.F.; investigation, P.K., K.F., M.R., and J.L.; resources, J.L. and P.K.; writing-original draft preparation, M.K.; writing-review and editing, P.K.; supervision, M.K.; project administration, M.K. and L.K.; funding acquisition, M.K. All authors have read and agreed to the published version of the manuscript.

Funding: This research was funded by the Czech Health Research Council (project no. NV18-0500340), grant IGA_LF_2021_022, project LO1304, and by MH CZ—DRO (FNOL, 00098892).

Institutional Review Board Statement: The study was conducted according to the guidelines of the Declaration of Helsinki. Ethics committee approval was not required as the study did not interfere with the diagnostic and therapeutic process.

Informed Consent Statement: Patients' parents gave written informed consent to sample collection, anonymous enrollment in the study and publication of the results.

Data Availability Statement: The support data are not publicly available due to privacy issues.

Acknowledgments: The authors thank Michaela Varejkova (Department of Probability and Mathematical Statistics, Faculty of Mathematics and Physics, Charles University, Prague, Czech Republic) for help in the statistical processing of the results and Pavel Kurfürst for proofreading.

Conflicts of Interest: The authors declare no conflict of interest. The funders had no role in the design of the study; in the collection, analyses, or interpretation of data; in the writing of the manuscript; or in the decision to publish the results.

\section{References}

1. Shah, B.A.; Padbury, J.F. Neonatal sepsis. Virulence 2014, 5, 170-178. [CrossRef] [PubMed]

2. Cortese, F.; Scicchitano, P.; Gesualdo, M.; Filaninno, A.; De Giorgi, E.; Schettini, F.; Laforgia, N.; Ciccone, M.M. Early and Late Infections in Newborns: Where Do We Stand? A Review. Pediatr. Neonatol. 2016, 57, 265-273. [CrossRef]

3. Tzialla, C.; Borghesi, A.; Pozzi, M.; Stronati, M. Neonatal infections due to multi-resistant strains: Epidemiology, current treatment, emerging therapeutic approaches and prevention. Clin. Chim. Acta 2015, 451, 71-77. [CrossRef] [PubMed]

4. McMillan, J.A.; Weiner, L.B.; Lamberson, H.V.; Hagen, J.H.; Aubry, R.H.; Abdul-Karim, R.W.; Sunderji, S.G.; Higgins, A.P. Efficacy of maternal screening and therapy in the prevention of chlamydia infection of the newborn. Infection 1985, 13, 263-266. [CrossRef] [PubMed]

5. Darville, T. Chlamydia trachomatis Infections in Neonates and Young Children. Semin. Pediatr. Infect. Dis. 2005, 16, 235-244. [CrossRef]

6. Santos, R.P.; Tristram, D. A Practical Guide to the Diagnosis, Treatment, and Prevention of Neonatal Infections. Pediatr. Clin. N. Am. 2015, 62, 491-508. [CrossRef]

7. Mukhopadhyay, S.; Wade, K.C.; Puopolo, K.M. Drugs for the Prevention and Treatment of Sepsis in the Newborn. Clin. Perinatol. 2019, 46, 327-347. [CrossRef]

8. Poirel, L.; Madec, J.-Y.; Lupo, A.; Schink, A.-K.; Kieffer, N.; Nordmann, P.; Schwarz, S. Antimicrobial Resistance in Escherichia coli. Microbiol. Spectr. 2018, 6, 289-316. [CrossRef] 
9. European Centre for Disease Prevention and Control. Data from the ECDC Surveillance Atlas-Antimicrobial resistance. Available online: https:/ / www.ecdc.europa.eu/en/antimicrobial-resistance/surveillance-and-disease-data/data-ecdc (accessed on 5 May 2020).

10. Paitan, Y. Current Trends in Antimicrobial Resistance of Escherichia coli. Curr. Top. Microbiol. Immunol. 2018, 416, 181-211. [CrossRef]

11. Stoll, B.J.; Hansen, N.I.; Sánchez, P.J.; Faix, R.G.; Poindexter, B.B.; Van Meurs, K.P.; Bizzarro, M.J.; Goldberg, R.N.; Frantz, I.D.; Hale, E.C.; et al. Early Onset Neonatal Sepsis: The Burden of Group B Streptococcal and E. coli Disease Continues. Pediatrics 2011, 127, 817-826. [CrossRef]

12. Ocviyanti, D.; Wahono, W.T. Risk Factors for Neonatal Sepsis in Pregnant Women with Premature Rupture of the Membrane. J. Pregnancy 2018, 2018, 1-6. [CrossRef]

13. Camacho-Gonzalez, A.; Spearman, P.W.; Stoll, B.J. Neonatal Infectious Diseases. Pediatr. Clin. N. Am. 2013, 60, 367-389. [CrossRef] [PubMed]

14. Shane, A.L.; Stoll, B.J. Neonatal sepsis: Progress towards improved outcomes. J. Infect. 2014, 68, S24-S32. [CrossRef]

15. Cho, H.J.; Cho, H.-K. Central line-associated bloodstream infections in neonates. Korean J. Pediatr. 2019, 62, 79-84. [CrossRef] [PubMed]

16. Dong, H.; Cao, H.; Zheng, H. Pathogenic bacteria distributions and drug resistance analysis in 96 cases of neonatal sepsis. BMC Pediatr. 2017, 17, 1-6. [CrossRef] [PubMed]

17. Cohen-Wolkowiez, M.; Moran, C.; Benjamin, D.K.; Cotten, C.M.; Clark, R.H.; Smith, P.B. Early and Late Onset Sepsis in Late Preterm Infants. Pediatr. Infect. Dis. J. 2009, 28, 1052-1056. [CrossRef] [PubMed]

18. Hornik, C.; Fort, P.; Clark, R.; Watt, K.; Benjamin, D.; Smith, P.; Manzoni, P.; Jacqz-Aigrain, E.; Kaguelidou, F.; Cohen-Wolkowiez, M. Early and late onset sepsis in very-low-birth-weight infants from a large group of neonatal intensive care units. Early Hum. Dev. 2012, 88, S69-S74. [CrossRef]

19. Alcock, G.; Liley, H.G.; Cooke, L.; Gray, P.H. Prevention of neonatal late-onset sepsis: A randomised controlled trial. BMC Pediatr. 2017, 17, 98. [CrossRef]

20. Folgori, L.; Bielicki, J. Future Challenges in Pediatric and Neonatal Sepsis: Emerging Pathogens and Antimicrobial Resistance. J. Pediatr. Intensiv. Care 2019, 8, 17-24. [CrossRef] [PubMed]

21. Zea-Vera, A.; Ochoa, T.J. Challenges in the diagnosis and management of neonatal sepsis. J. Trop. Pediatr. 2015, 61, 1-13. [CrossRef] [PubMed]

22. Russell, A.R.B. Neonatal sepsis. Paediatr. Child Health 2011, 21, 265-269. [CrossRef]

23. Shane, A.L.; Sánchez, P.J.; Stoll, B.J. Neonatal sepsis. Lancet 2017, 390, 1770-1780. [CrossRef]

24. Bulkowstein, S.; Ben-Shimol, S.; Givon-Lavi, N.; Melamed, R.; Shany, E.; Greenberg, D. Comparison of early onset sepsis and community-acquired late onset sepsis in infants less than 3 months of age. BMC Pediatr. 2016, 16, 1-8. [CrossRef] [PubMed]

25. Greenberg, R.G.; Benjamin, D.K. Neonatal candidiasis: Diagnosis, prevention, and treatment. J. Infect. 2014, 69, S19-S22. [CrossRef]

26. Hope, W.; Castagnola, E.; Groll, A.; Roilides, E.; Akova, M.; Arendrup, M.; Arikan-Akdagli, S.; Bassetti, M.; Bille, J.; Cornely, O.; et al. ESCMID* guideline for the diagnosis and management of Candida diseases 2012: Prevention and management of invasive infections in neonates and children caused by Candida spp. Clin. Microbiol. Infect. 2012, 18, 38-52. [CrossRef]

27. Roilides, E. Invasive candidiasis in neonates and children. Early Hum. Dev. 2011, 87, S75-S76. [CrossRef]

28. Straková, L.; Motlová, J. Active surveillance of early onset disease due to group B streptococci in newborns. Indian J. Med. Res. 2004, 119, 205-207. [PubMed]

29. Simetka, O.; Petros, M.; Podesvová, H. Prevention of early-onset neonatal group B streptococcal infection: Neonatal outcome after introduction of national screening guideline. Ceska Gynekol. 2010, 75, 41-46.

30. Van Dyke, M.K.; Phares, C.R.; Lynfield, R.; Thomas, A.R.; Arnold, K.E.; Craig, A.S.; Mohle-Boetani, J.; Gershman, K.; Schaffner, W.; Petit, S.; et al. Evaluation of Universal Antenatal Screening for Group B Streptococcus. New Engl. J. Med. 2009, 360, $2626-2636$. [CrossRef]

31. Boyer, K.M.; Gotoff, S.P. Prevention of Early-Onset Neonatal Group B Streptococcal Disease with Selective Intrapartum Chemoprophylaxis. N. Engl. J. Med. 1986, 314, 1665-1669. [CrossRef]

32. American Academy of Pediatrics Committee on Infectious Diseases and Committee on Fetus and Newborn. Revised guidelines for prevention of early-onset group B streptococcal (GBS) infection. Pediatrics 1997, 99, 489-496. [CrossRef] [PubMed]

33. Croxatto, A.; Prod'hom, G.; Greub, G. Applications of MALDI-TOF mass spectrometry in clinical diagnostic microbiology. FEMS Microbiol. Rev. 2012, 36, 380-407. [CrossRef] [PubMed]

34. The European Committee on Antimicrobial Susceptibility Testing_EUCAST. Available online: https://www.eucast.org/ (accessed on 10 January 2015).

35. Röderova, M.; Halova, D.; Papousek, I.; Dolejska, M.; Masarikova, M.; Hanulik, V.; Pudova, V.; Broz, P.; Htoutou-Sedlakova, M.; Sauer, P.; et al. Characteristics of Quinolone Resistance in Escherichia coli Isolates from Humans, Animals, and the Environment in the Czech Republic. Front. Microbiol. 2017, 7, 2147. [CrossRef] 
36. Husickova, V.; Cekanova, L.; Chroma, M.; Htoutou-Sedlakova, M.; Hricova, K.; Kolář, M. Carriage of ESBL- and AmpC-positive Enterobacteriaceae in the gastrointestinal tract of community subjects and hospitalized patients in the Czech Republic. Biomed. Pap. 2012, 156, 348-353. [CrossRef] [PubMed]

37. Tenover, F.C.; Arbeit, R.D.; Goering, R.V.; Mickelsen, P.A.; Murray, B.E.; Persing, D.H.; Swaminathan, B. Interpreting chromosomal DNA restriction patterns produced by pulsed-field gel electrophoresis: Criteria for bacterial strain typing. J. Clin. Microbiol. 1995, 33, 2233-2239. [CrossRef] 